13

\title{
Модификация кобальтом тонких пленок рутила при магнетронном распылении и вакуумном отжиге
}

\author{
(C) Н.Н. Афоонин, ${ }^{1}$ В.А. Логачева ${ }^{2}$ \\ ${ }^{1}$ Воронежский государственный педагогический университет, \\ 394043 Воронеж, Россия \\ ${ }^{2}$ Воронежский государственный университет, \\ 394018 Воронеж, Россия \\ e-mail: nafonin@vspu.ac.ru
}

(Поступило в Редакцию 13 июля 2017 г.)

Методами рентгенофазового анализа, атомно-силовой микроскопии и вторично-ионной спектрометрии исследовано фазообразование и перераспределение компонентов в пленочной системе $\mathrm{Co}-\mathrm{TiO}_{2}$ при магнетронном распылении металла на оксид и в ходе последующего вакуумного отжига. Установлена глубокая диффузия кобальта в оксид титана и образование сложных оксидов состава: $\mathrm{CoTi}_{2} \mathrm{O}_{5}$ и $\mathrm{CoTiO}_{3}$. Предложен механизм их формирования на границах зерен по всей толщине пленки $\mathrm{TiO}_{2}$, предполагающий реакционную диффузию кобальта по межзеренным границам оксида. Разработана количественная модель реакционной взаимодиффузии в двухслойных пленочных поликристаллических системах металл-оксид с ограниченной растворимостью компонентов. Определены значения индивидуальных коэффициентов диффузии кобальта и титана в диапазоне температур $923-1073 \mathrm{~K}$.

DOI: $10.21883 /$ JTF.2018.04.45734.2436

\section{Введение}

Широкозонные металл-оксидные полупроводники, такие как $\mathrm{TiO}_{2}$ (рутил, анатаз), в которых небольшая часть катионов замещена магнитными ионами, могут проявлять ферромагнитные свойства при комнатной температуре, сохраняя при этом свойства незамещенного полупроводника. В ряде работ показано, что пленки оксида титана, легированные кобальтом, проявляют ферромагнитный отклик при комнатной температуре и выше [1-3]. В литературе приводятся данные по магнетизму рутила, имплантированного кобальтом [4,5], согласно которым в системе имеет место формирование двух магнитных фаз: магнитные наночастицы металлического кобальта как на поверхности, так и в объеме образца, и твердые растворы, в которых парамагнитные $\mathrm{Co}^{2+}$-ионы изоморфно замещают ионы $\mathrm{Ti}^{4+}$ в матрице $\mathrm{TiO}_{2}$ [6]. При высоком уровне легирования пленок рутила кобальтом образуются стабильные субоксидные фазы $\mathrm{CoTi}_{4} \mathrm{O}_{2}$, которые, по мнению авторов [7], и являются причиной высокотемпературного ферромагнетизма в пленках состава $\mathrm{Ti}_{0.95} \mathrm{Co}_{0.05} \mathrm{O}_{2}$. В ходе термического отжига металлической пленки Со толщиной $3 \mathrm{~nm}$ на поверхности $\mathrm{TiO}_{2}$ (100) было обнаружено, что взаимодействие начинается при температуре выше $673 \mathrm{~K}$ [8]. При этом металлические атомы кобальта окисляются до $\mathrm{Co}^{+2}, \mathrm{a} \mathrm{Ti}^{+4}$ восстанавливается до $\mathrm{Ti}^{+3}$.

Легированные кобальтом объемные образцы анатаза и рутила, полученные в [9] золь-гель методом, были парамагнитными при комнатной температуре. Только дальнейший отжиг в среде $\mathrm{Ar} / \mathrm{H}_{2}$ приводит к их ферромагнитному поведению. Исследования показали, что при низких уровнях легирования < 4\% после отжига происходит образование $\mathrm{CoTiO}_{3}$ в качестве новой фазы. Оксид $\mathrm{Co}_{3} \mathrm{O}_{4}$ был обнаружен в образцах анатаза с уровнями легирования $\mathrm{Co} \geq 4 \%$. Наблюдаемые оксиды Со восстанавливаются в среде $\mathrm{Ar} / \mathrm{H}_{2}$ до металлического Co. Таким образом, ферромагнетизм при комнатной температуре является следствием сегрегации металлического Со. Магнитные свойства пленок оксида титана, модифицированных кобальтом, определяются уровнем легирования и характером распределения магнитных фаз по всей толщине пленки.

В [10] предложена модель перераспределения в монокристаллическом рутиле введенной методом ионной имплантации примеси кобальта в процессе последующего отжига. Модель учитывает распыление материала во время ионной имплантации, быструю одномерную диффузию примеси вдоль структурного канала в рутиле и преципитацию внедряемой примеси на разных глубинах.

Приводимые в $[10,11]$ значения коэффициентов диффузии Со в монокристаллическом рутиле значительно различаются. Если процессы фазообразования при ионной имплантации кобальта в монокристаллический рутил в ряде работ $[7,8,12]$ обсуждаются, то представления о механизме диффузии кобальта в поликристаллическом рутиле, сопровождаемом фазообразованием, неразвиты.

Целью настоящей работы является комплексное исследование механизма взаимодействия кобальта с тонкими пленками оксида титана.

\section{Методика эксперимента}

Поликристаллические пленки оксида титана в структуре рутила получали путем магнетронного распыления 
металлического титана на подложки монокристаллического кремния с последующим его термооксидированием в потоке кислорода при атмосферном давлении при $T=973 \mathrm{~K}$ в течение $30 \mathrm{~min}$.

Пленки оксида титана модифицировали магнетронным распылением кобальта в модернизированной установке УВН-1 в плазме аргона при режимах: давление в камере $13.3 \cdot 10^{-2} \mathrm{~Pa}$, ток разряда $0.5 \mathrm{~A}$, напряжение разряда $420 \mathrm{~V}$; с последующим отжигом в вакууме в диапазоне температур $873-1073 \mathrm{~K}$ в течение $30 \mathrm{~min}$. Материалом катода служила мишень металлического кобальта с содержанием примесей не более 0.01 ат.\%. Скорость распыления кобальта составила $1.13 \mathrm{~nm} / \mathrm{s}$, толщина пленки задавалась временем распыления и составляла $100 \mathrm{~nm}$.

Дифрактометрическое исследование in-situ фазовых превращений в пленочной системе $\mathrm{CoTiO}_{2} / \mathrm{Si}$ в процессе изотермического отжига в температурном интервале от 303 до $1073 \mathrm{~K}$ проводили в вакуумной камере дифрактометра ARL X'TRA при давлении $P=1.33 \cdot 10^{-2} \mathrm{~Pa} \mathrm{c}$ использованием $\mathrm{Cu} K_{\alpha}-1$ излучения $(\lambda=1.540562 \AA)$ в интервале углов $20-80^{\circ}$ с шагом $0.06^{\circ}$. Идентификация фазового состава пленочных образцов проведена путем сопоставления набора межплоскостных расстояний и интенсивностей с Международной базой данных JCPDS-ICDD [13]. Распределения компонентов по глубине пленочной системы определяли методом вторично-ионной масс-спектрометрии (ВИМС) на установке Cameca IMS7f с использованием пучка первичных ионов $\mathrm{Cs}^{+}$с энергией $3 \mathrm{keV}$.

Исследование морфологии поверхности пленок проводили методом атомно-силовой микроскопии (ACM) на сканирующем зондовом микроскопе Solver P47PRO в полуконтактном режиме с использованием кантилевера NSG11S. Магнитная силовая микроскопия (МСM) образцов была проведена с использованием высокоразрешающего неконтактного зонда марки fpNO3-Co. Радиус закругления зондов составлял $\sim 30 \mathrm{~nm}$.

\section{Экспериментальные результаты и их обсуждение}

В полученной магнетронным распылением пленке методом РФА были обнаружены следующие фазы: оксид титана в структуре рутила $\left(\mathrm{TiO}_{2}\right)$, металлический кобальт кубической структуры, титанат кобальта $\left(\mathrm{CoTi}_{2} \mathrm{O}_{5}\right)$ орторомбической структуры с параметрами решетки: $a=3.728, b=9.788, c=$ $=10.067 \AA$ (рис. 1, кривая 1). $\mathrm{CoTiO}_{3}$ ромбоэдрической модификации с параметрами решетки: $a=5.044$, $b=5.044, c=13.961 \AA$ формируется при $T=573 \mathrm{~K}$. Увеличение температуры последующего отжига приводит к образованию при $T=673 \mathrm{~K}$ интерметаллида $\mathrm{Co}_{3}$ Ті кубической структуры с параметром решетки $a=$ $=3.614 \AA$, а при $T=773 \mathrm{~K}$ появляется фаза силицида титана $\mathrm{Ti}_{5} \mathrm{Si}_{4}$ орторомбической модификации: $a=6.645$,

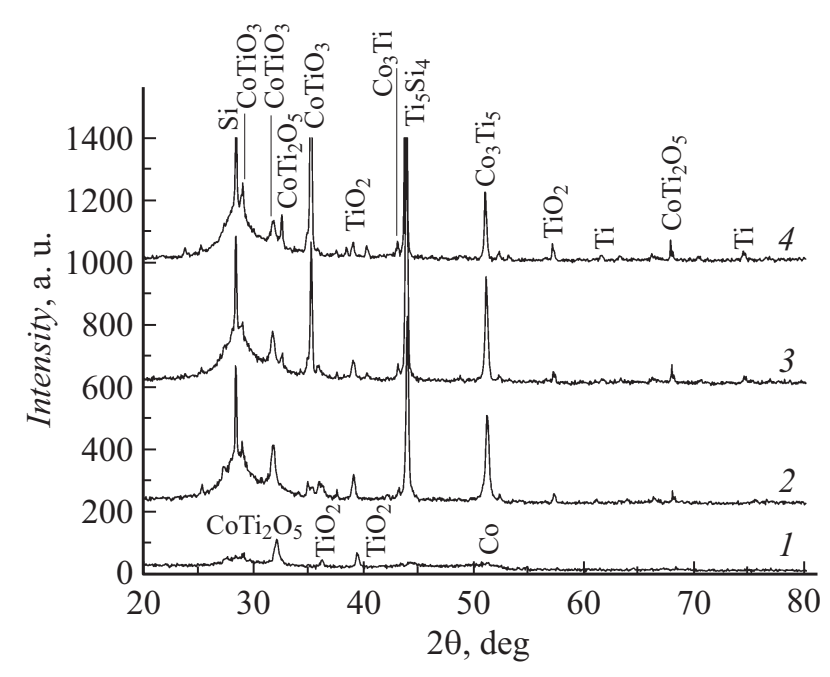

Рис. 1. Дифрактограмма пленочной системы $\mathrm{Co}-\mathrm{TiO}_{2}$ : после магнетронного распыления кобальта $(1)$ и вакуумного отжига при $T=773$ (2), 873 (3), $1073 \mathrm{~K}(4)$.

$b=12.690, c=12.69 \AA$ (рис. 1, кривая 2). После отжига при $873-1073 \mathrm{~K}$ на дифрактограмме растет интенсивность рефлекса, принадлежащего $\mathrm{CoTiO}_{3}$ ромбоэдрической модификации (рис. 1, кривые 3,4 ). Образование $\mathrm{CoTiO}_{3}$ наблюдали и в [14] после отжига при $923 \mathrm{~K}$ пленки $\mathrm{Co}-\mathrm{TiO}_{2}$, полученной золь-гель способом на подложках монокристаллического кремния и кварца. Экспериментальные результаты [15] показывают, что легирование кобальтом происходит в результате введения ионов $\mathrm{Co}^{2+}$ в решетку $\mathrm{TiO}_{2}\left(\mathrm{Ti}^{4+}\right)$ и ингибирует рост размеров кристаллитов рутила. Более того, при высокой температуре обнаружено сосуществование фазы $\mathrm{CoTiO}_{3}$ с высококристаллическим рутилом. В наших экспериментах по модификации тонкопленочного рутила кобальтом при $T=1073 \mathrm{~K}$ в пленке остается фаза рутила и металлического титана наряду с фазами сложных оксидов титана и кобальта: $\mathrm{CoTiO}_{3}$ и $\mathrm{CoTi}_{2} \mathrm{O}_{5}$.

$\mathrm{ACM}$-изображения пленки $\mathrm{Co}-\mathrm{TiO}_{2} / \mathrm{Si}$ после вакуумного отжига представлены на рис. 2,a. Формируемая пленка имеет гладкую поверхность со средним значением шероховатости $22.6 \mathrm{~nm}$ (рис. 2,b) с характерным размером зерна $40-75 \mathrm{~nm}$, высотой $(Z)$ от 1.1 до $4 \mathrm{~nm}$ (рис. 2,c). Пленки имеют однородный рельеф поверхности с максимальной плотностью распределения размера зерен в диапазоне от 40 до $60 \mathrm{~nm}$ (рис. 2, $d$ ).

Фазовый контраст и МСМ-изображение (рис. 3) свидетельствуют о том, что пленки представляют собой однородную систему с включением отдельных магнитных фаз.

На рис. 4, 5 представлены полученные методом ВИМС распределения кобальта и титана по глубине пленочной системы $\mathrm{Co}-\mathrm{TiO}_{2} / \mathrm{Si}$ после магнетронного распыления и последующего вакуумного отжига. Как видно из рис. 4, полученная магнетронным распылением пленка состоит из двух слоев: внешнего металлического 
$a$

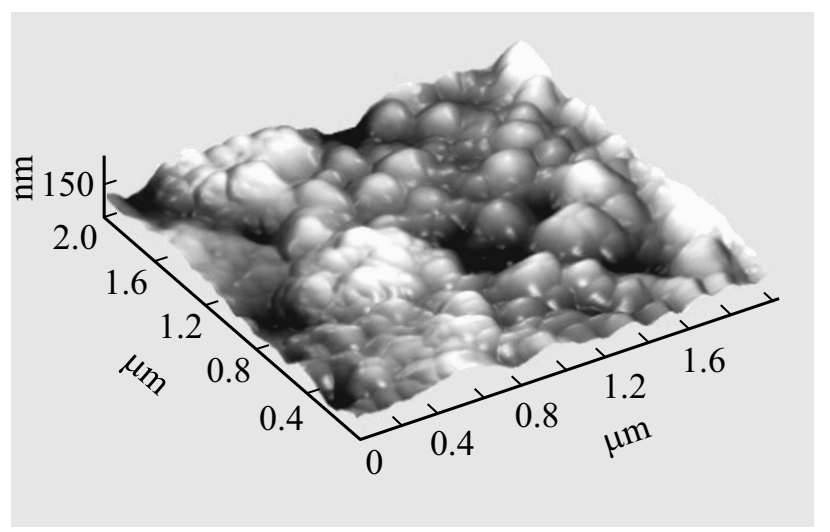

$c$

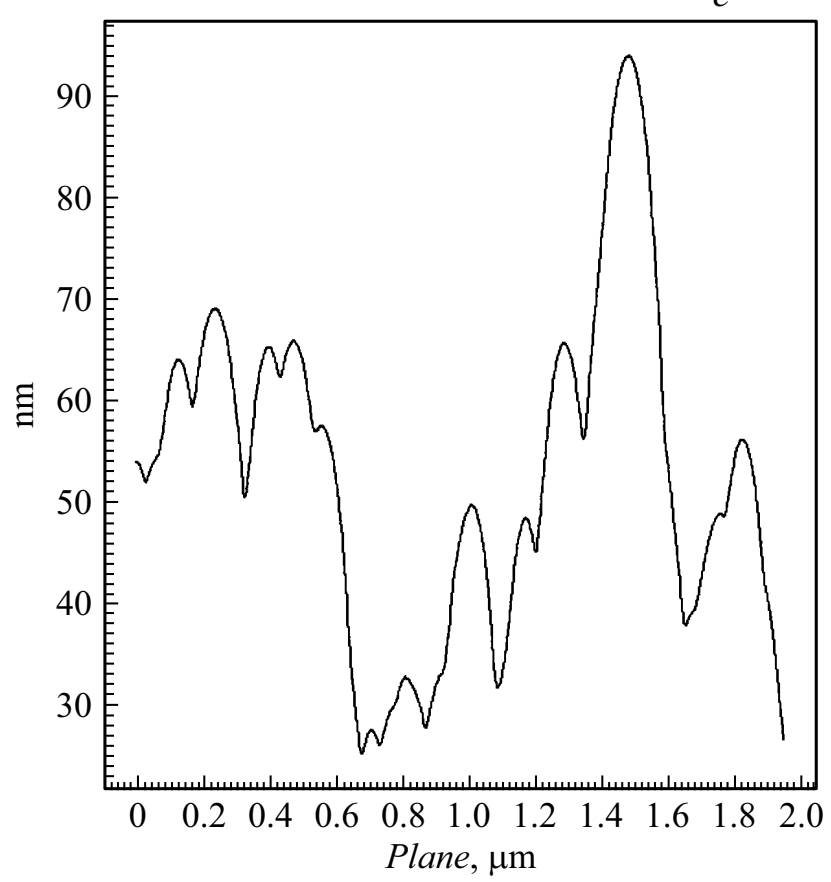

$b$

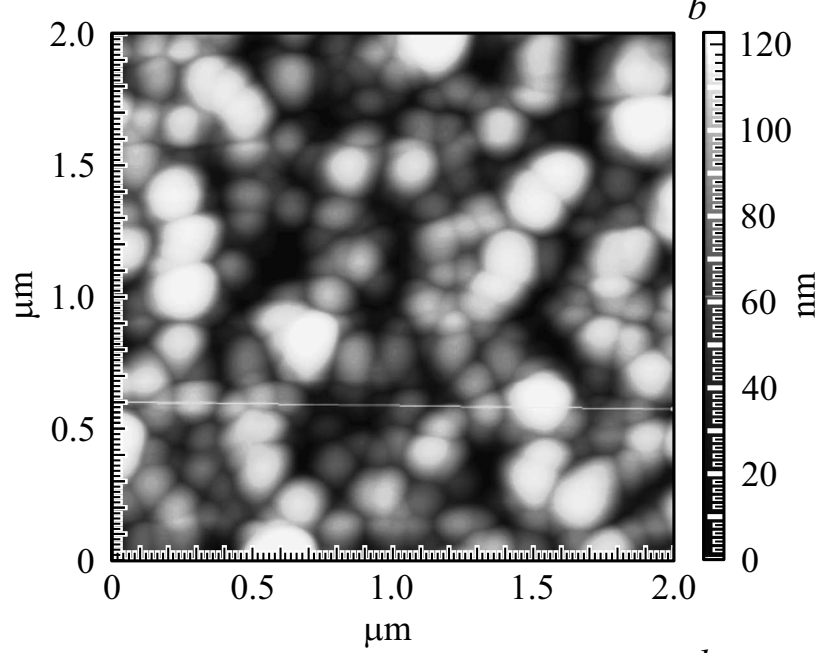

$d$

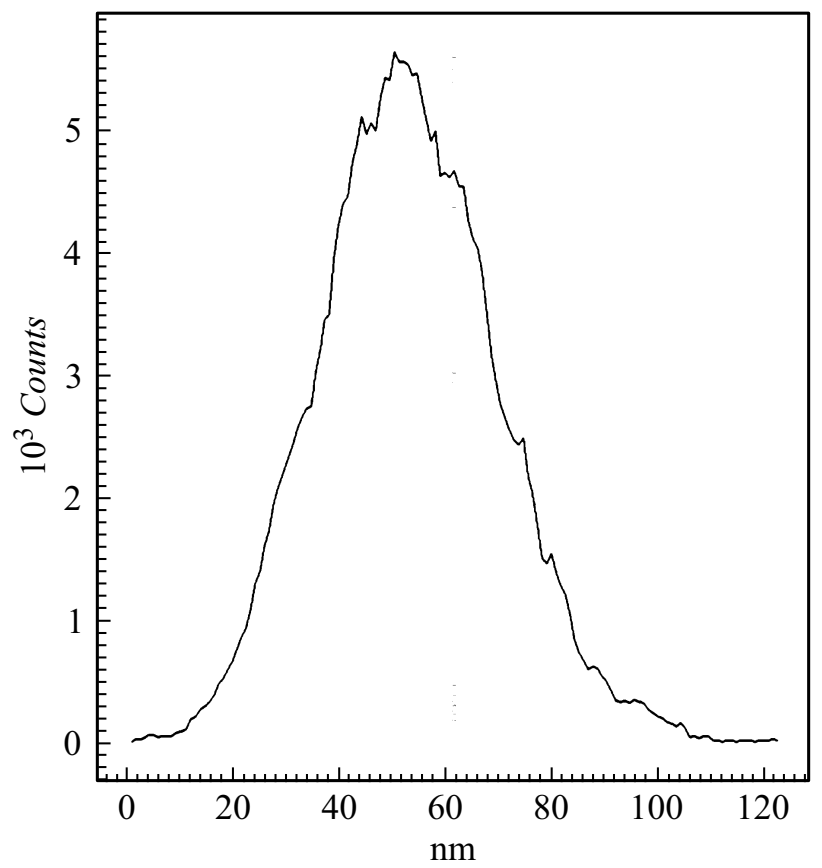

Рис. 2. АСМ-изображение поверхности $2 \times 2 \mu \mathrm{m}^{2}$ пленочной системы $\mathrm{Co}-\mathrm{TiO}_{2} / \mathrm{Si}$ после отжига в вакууме при $T=1073 \mathrm{~K}$ : $a-3 \mathrm{D}$-изображение поверхности, $b-$ сечение рельефа поверхности, $c$ - сечение рельефа поверхности структуры, $d-$ гистограмма плотности распределения значений высоты $(Z)$ для всего изображения.

слоя кобальта толщиной $\sim 100 \mathrm{~nm}$ и оксида титана толщиной $\sim 250 \mathrm{~nm}$. Характер концентрационных распределений свидетельствует о том, что перемешивание компонентов происходит уже в процессе магнетронного распыления, причем размер переменной по концентрации области $(\sim 30 \mathrm{~nm})$ соизмерим с толщиной нанесенной пленки кобальта (рис. 4, точки 1,2). В ходе последующего вакуумного отжига при $T=923 \mathrm{~K}$ наблюдается глубокое проникновение кобальта в рутил и появление титана в пленке кобальта (рис. 4, точки 3,4). Характер распределения титана свидетельствует о его встречном потоке в металлическую пленку кобальта, где при температуре $T=873 \mathrm{~K} \mathrm{он} \mathrm{взаимодействует} \mathrm{с} \mathrm{Со} \mathrm{с}$ образованием интерметаллида $\mathrm{Co}_{3} \mathrm{Ti}$, о чем свидетельствуют данные РФА (рис. 1).

В ходе последующего вакуумного отжига до температуры $T=1073 \mathrm{~K}$ наблюдается дальнейшее глубокое проникновение кобальта в рутил и появление титана в пленке кобальта с увеличением его концентрации на внешней границе (рис. 5,a). При температуре отжига $T=1073 \mathrm{~K}$ количество (доза) кобальта в пленке оксида титана увеличивается в $\sim 5$ раз до концентрации $\sim 10^{21} \mathrm{~cm}^{-3}$ (рис. $5, b$ ) по сравнению с исходной пленочной системой после магнетронного распыления.

Наблюдаемые результаты экспериментальных исследований можно объяснить в предположении реакцион- 

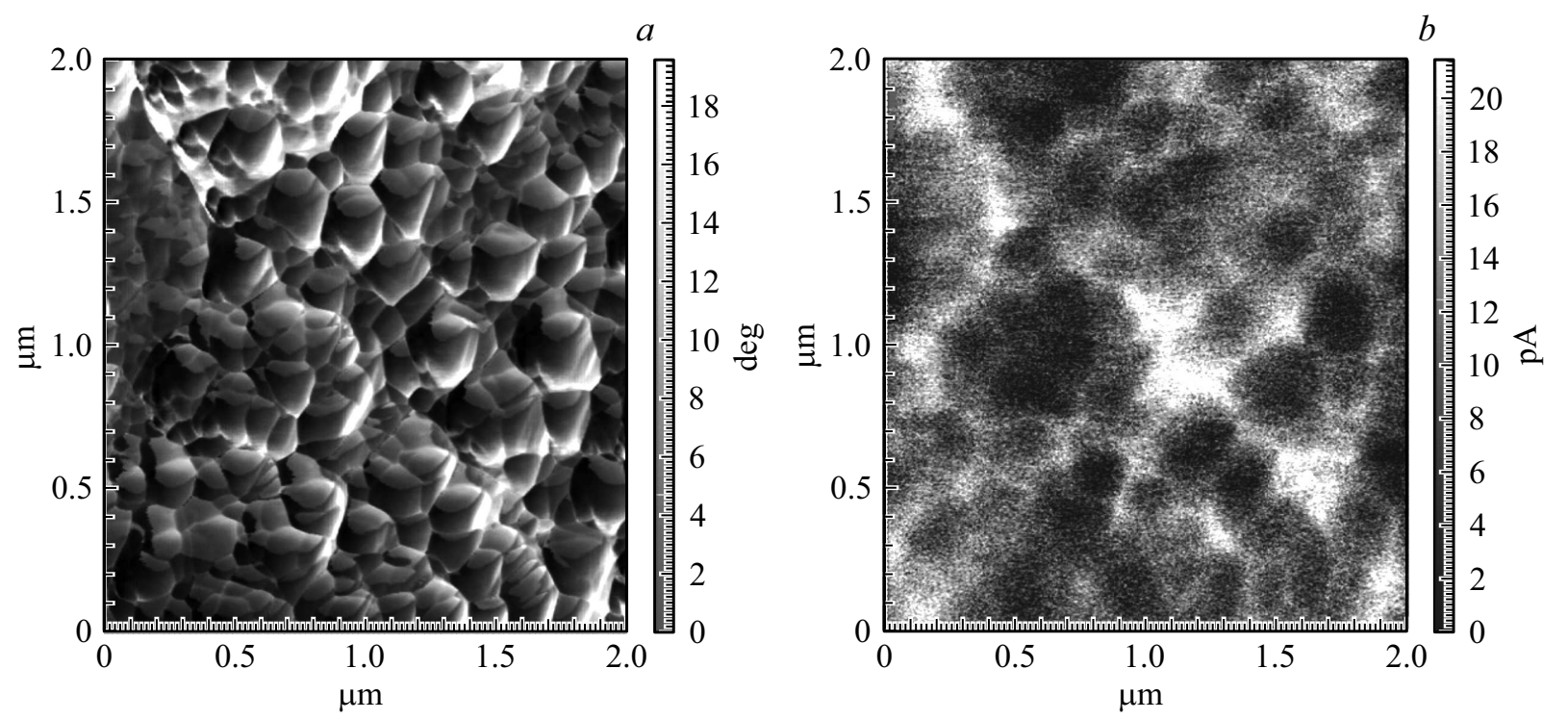

Рис. 3. Фазовый контраст $(a)$ и МСМ-изображение $(b)$ поверхности пленочной системы $\mathrm{Co}-\mathrm{TiO}_{2} / \mathrm{Si}$ после вакуумного отжига при $T=1073 \mathrm{~K}$.

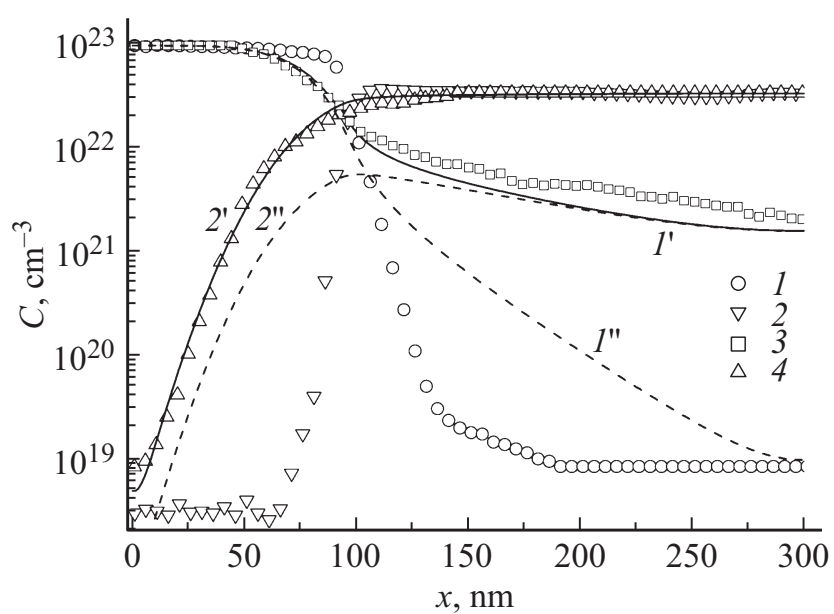

Рис. 4. Экспериментальные (метод ВИМС) (точки 1-4) и расчетные (кривые $\left.1^{\prime}, 2^{\prime}, 1^{\prime \prime}, 2^{\prime \prime}\right)$ распределения по глубине пленочной системы $\mathrm{Co}-\mathrm{TiO}_{2}$ полной $\left(1^{\prime}, 2^{\prime}\right)$ и свободной части $\left(1^{\prime \prime}, 2^{\prime \prime}\right)$ концентрации $C$ металлов. $1,2-$ после магнетронного распыления, $3,4-$ после вакуумного отжига при $T=923 \mathrm{~K}$ $(1,3-\mathrm{Co}, 2,4-\mathrm{Ti})$.

ной диффузии кобальта в оксид титана с образованием фаз сложных оксидов по глубине пленки $\mathrm{TiO}_{2}$.

\section{Модель и результаты численного анализа}

Растворимость Со в $\mathrm{TiO}_{2}$ зависит от способа модифицирования оксида титана, структуры самого оксида и варьирует от 2 до 10\%. В работе [16] установлено 10\%-ное содержание Со в пленках $\mathrm{TiO}_{2}$, осажденных на подложки $\mathrm{SrTiO}_{3}$. В пленках $\mathrm{TiO}_{2}$ на подложках
$\mathrm{LaAlO}_{3}$ получали твердый раствор $\mathrm{Co}_{x} \mathrm{Ti}_{1-x} \mathrm{O}_{2}$ с содержанием $\mathrm{Co} \sim 8 \%$ [17]. Пленки $\mathrm{TiO}_{2}$, осажденные магнетронным распылением на стеклянные подложки, сохраняли структуру анатаза при содержании Со до 2.51\%, причем отжиг до температуры $773 \mathrm{~K}$ показал глубокую диффузию кобальта в пленке оксида титана [18]. Был определен интервал концентраций, при которых происходит встраивание кобальта в решетку оксида титана, и предел концентраций, при котором металлический кобальт выделяется в виде нанокластеров [19]. Превышение значения критической величины концентрации кобальта $\left(\sim 10^{20} \mathrm{~cm}^{-3}\right)$ ведет к зарождению и росту наноразмерных частиц металла.

$\mathrm{B}$ пленке $\mathrm{TiO}_{2}$, имеющей поликристаллическую структуру, можно ожидать более высокой растворимости вследствие накопления кобальта в межзеренном пространстве и его способности замещать титан в катионных позициях оксида. Будем полагать, что проникновение кобальта внутрь кристаллитов оксида титана отсутствует.

Диффундируя по границам зерен, кобальт испытывает сегрегационный захват на них. Центрами захвата выступают координационно-ненасыщенные атомы титана, выходящие на поверхность зерен. Атомы Со, мигрирующие в пленке $\mathrm{TiO}_{2}$, иммобилизуются на границах зерен $\mathrm{TiO}_{2}$ как на ловушках, теряя свою подвижность. Эта стадия процесса, вероятно, носит характер физической сорбции, без химического взаимодействия.

На следующей стадии процесса происходит замещение кобальтом титана в оксиде с высвобождением свободного, способного к миграции титана. Атомы кобальта способствуют ослаблению и разрыву соседних ковалентных связей полупроводника, в нашем случае $\mathrm{TiO}_{2}$, и замене их на связи $\mathrm{Co}-\mathrm{O}$ с восстановлением 

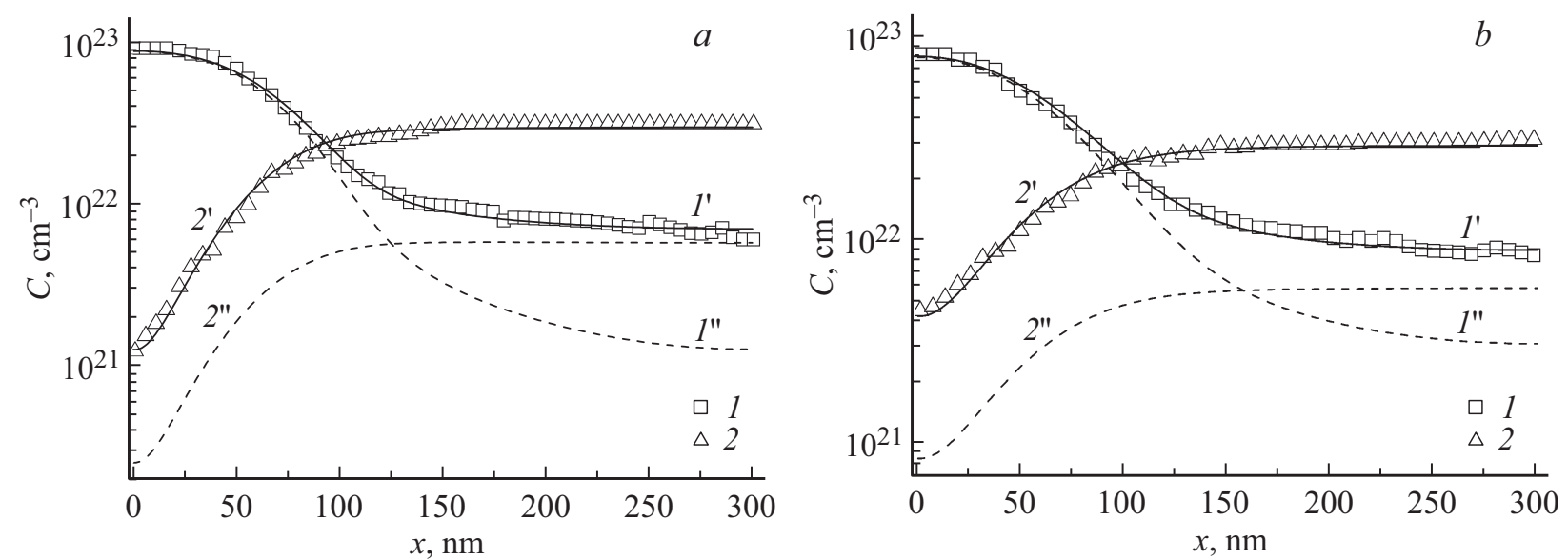

Рис. 5. Экспериментальные (метод ВИМС) (точки 1,2$)$ и расчетные (кривые $1^{\prime}, 2^{\prime}, 1^{\prime \prime}, 2^{\prime \prime}$ ) распределения по глубине пленочной системы Со- $\mathrm{TiO}_{2}$ полной $\left(1^{\prime}, 2^{\prime}\right)$ и свободной части $\left(1^{\prime \prime}, 2^{\prime \prime}\right)$ концентрации $C$-металлов. $1-\mathrm{Co}, 2-\mathrm{Ti}$; кривые: $1^{\prime}, 1^{\prime \prime}-\mathrm{Co}$, $2^{\prime}, 2^{\prime \prime}$ - Ті после вакуумного отжига при $T=1023(a)$ и $1073 \mathrm{~K}(b)$.

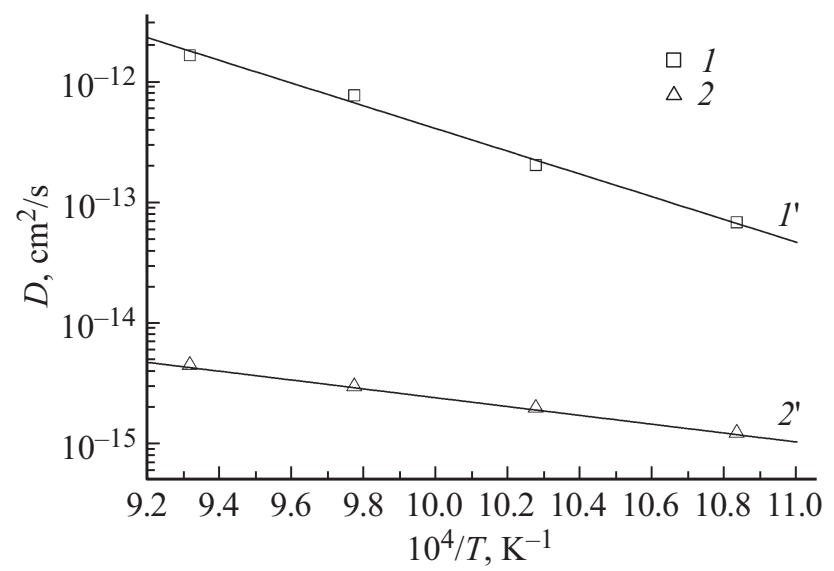

Рис. 6. Температурная зависимость индивидуальных коэффициентов диффузии металлов в пленочной системе $\mathrm{Co}-\mathrm{TiO}_{2}$. Точки - результаты численного анализа для кобальта (1) и титана (2); кривые $1^{\prime}, 2^{\prime}-$ аппроксимации уравнением Аррениуса для кобальта (12) и титана (13).

титана в элементарной форме:

$$
\mathrm{A}+\mathrm{B} \stackrel{k_{1}}{\longrightarrow} \mathrm{D}+\mathrm{C}
$$

где А - свободный кобальт, В - титан, содержащийся на межзеренных границах его оксида, С - свободный титан, D - кобальт в составе сложного оксида, заменивший титан в $\mathrm{TiO}_{2}$ на границе зерен, $k_{1}-$ константа скорости реакции.

Захват кобальта на межзеренных границах $\mathrm{TiO}_{2}$ будет происходить до тех пор, пока не будет переведен в свободную форму весь имеющийся на них титан. Кобальт не проникает в глубь зерен оксида вследствие низкой растворимости. Поэтому даже при высоких температурах на развитой стадии процесса Со не может заместить весь находящийся в пленке оксида связанный с кислородом Ті. Замещенные кобальтом атомы титана частично диффундируют в пленку металлического кобальта, а оставшиеся в пленке $\mathrm{TiO}_{2}$ вместе со вступившим в химическую связь с кислородом кобальтом дают основу для образования на поверхности зерен оксида титана обнаруженных РФА в условиях эксперимента сложных оксидов кобальта и титана: $\mathrm{CoTi}_{2} \mathrm{O}_{5}$ и $\mathrm{CoTiO}_{3}$.

В результате исходная пленка $\mathrm{TiO}_{2}$ становится гетерофазной. Образовавшиеся сложные оксиды распределены внутри довольно протяженной реакционной зоны, соизмеримой с исходной пленкой $\mathrm{TiO}_{2}$. Это свидетельствует о том, что процесс фазообразования контролируется не твердофазной реакцией, а диффузией подвижных компонентов - свободного кобальта и титана. Образование оксидов происходит в этом случае не путем послойного роста на границе раздела фаз, а по всей толщине пленки по границам зерен $\mathrm{TiO}_{2}$.

Подвижными компонентами в реакции (1) являются атомы свободного Со и Тi, образовавшегося в результате замещения его кобальтом на поверхности зерен оксида титана. Если начало системы отсчета положить на внешней границе пленки кобальта, то при соотношении индивидуальных коэффициентов диффузии металлов $\left(D_{\mathrm{A}} \gg D_{\mathrm{C}}\right)$ на развитой стадии процесса имеем перемещение межфазной границы $\mathrm{Co}-\mathrm{TiO}_{2}$ к поверхности пленочной системы вследствие эффекта Киркендалла [20]. При этом структурные фрагменты оксида титана, находящиеся внутри зерен и не вступающие в химическое взаимодействие с кобальтом, будут эффективно перемещаться к внешней границе системы, играя роль инертных меток в опыте Смигельскаса и Киркендалла [20].

Согласно теории Даркена [21], в бинарной системе с неограниченной растворимостью взаимная диффузия описывается краевой задачей для двух уравнений, содержащих один эффективный коэффициент взаимодиффузии, являющийся линейной комбинацией индивидуальных коэффициентов диффузии компонентов. Одно из 
основных положений теории [21] связано с отсутствием учета возможных химических превращений в процессе взаимодиффузии и предположением о неизменности мольного объема системы, связанном с изменением его состава. В нашем случае оно обосновано тем, что образование твердых растворов замещения на основе оксида титана происходит на границах зерен при наличии достаточного свободного объема, а также тем, что в твердофазной реакции участвуют только зернограничные атомы титана, составляющие незначительную долю от всего связанного с кислородом титана в $\mathrm{TiO}_{2}$. Поэтому полагаем, что в системе $\mathrm{Co}-\mathrm{TiO}_{2}$ диффузионное перемешивание $\mathrm{Co}$, $\mathrm{Ti}$ (в составе $\mathrm{TiO}_{2}$ ) и восстановленного Ті также может быть описано с помощью эффективного коэффициента взаимодиффузии.

Уравнения задачи, описывающей взаимодиффузию в пленочной системе $\mathrm{Co}-\mathrm{TiO}_{2}$, учитывают реакцию на границах зерен с помощью введения кинетических (реакционных) членов и имеют вид

$$
\begin{aligned}
\frac{\partial C_{\mathrm{A}}}{\partial t}=\frac{\partial}{\partial x}\left(D^{*} \frac{\partial C_{\mathrm{A}}}{\partial x}\right)-k_{1}\left(C_{\mathrm{B}} C_{\mathrm{A}}\right), \\
\frac{\partial C_{\mathrm{B}}}{\partial t}=\frac{\partial}{\partial x}\left(D^{*} \frac{\partial C_{\mathrm{B}}}{\partial x}\right)-k_{1}\left(C_{\mathrm{B}} C_{\mathrm{A}}\right), \\
\frac{\partial C_{\mathrm{C}}}{\partial t}=\frac{\partial}{\partial x}\left(D^{*} \frac{\partial C_{\mathrm{C}}}{\partial x}\right)+k_{1}\left(C_{\mathrm{B}} C_{\mathrm{A}}\right), \\
\frac{\partial C_{\mathrm{D}}}{\partial t}=\frac{\partial}{\partial x}\left(D^{*} \frac{\partial C_{\mathrm{D}}}{\partial x}\right)+k_{1}\left(C_{\mathrm{B}} C_{\mathrm{A}}\right), \\
\frac{\partial C_{\mathrm{F}}}{\partial t}=\frac{\partial}{\partial x}\left(D^{*} \frac{\partial C_{\mathrm{F}}}{\partial x}\right),
\end{aligned}
$$

где $t$ - время, $x$ - глубина, отсчитываемая от внешней поверхности пленки металла, $C_{\mathrm{A}}, C_{\mathrm{B}}, C_{\mathrm{C}}, C_{\mathrm{D}}, C_{\mathrm{F}}-$ концентрации компонентов: $C_{\mathrm{A}}-$ свободного кобальта, $C_{\mathrm{B}}$ - титана на межзеренных границах оксида $\mathrm{TiO}_{2}$, участвующего в реакции замещения, $C_{\mathrm{C}}-$ свободного титана, $C_{\mathrm{D}}-$ связанного кобальта в составе сложного оксида и $C_{\mathrm{F}}$ - титана, входящего в состав стехиометрического оксида внутри зерен, не участвующего в реакции.

Эффективный коэффициент взаимодиффузии $D^{*}$ в нашем случае имеет вид

$$
D^{*}=\frac{D_{\mathrm{A}}\left(C_{\mathrm{B}}+C_{\mathrm{C}}\right)+D_{\mathrm{C}}\left(C_{\mathrm{A}}+C_{\mathrm{D}}\right)}{C_{t}},
$$

где $D_{\mathrm{A}}$ и $D_{\mathrm{C}}-$ индивидуальные коэффициенты диффузии свободных подвижных компонентов - кобальта и титана соответственно, $C_{t}=C_{\mathrm{A}}+C_{\mathrm{B}}+C_{\mathrm{C}}+C_{\mathrm{D}}-$ общая концентрация активных компонентов системы.

На границах пленочной системы $\mathrm{Co}-\mathrm{TiO}_{2}$ полагалось условие отражения:

$$
\frac{\partial C_{\mathrm{A}}}{\partial x}=\frac{\partial C_{\mathrm{B}}}{\partial x}=\frac{\partial C_{\mathrm{C}}}{\partial x}=\frac{\partial C_{\mathrm{D}}}{\partial x}=\frac{\partial C_{\mathrm{F}}}{\partial x}=0 \text { при } x=0 \text { и } x=L .
$$

Концентрационные распределения компонентов (рис. 4, точки 3, 4, рис. 5, точки 1, 2) в ходе последующего отжига в условиях эксперимента существенно отличаются от полученных в ходе магнетронного распыления (рис. 4, точки 1-2). Поэтому начальными условиями для уравнений (2)-(6) при моделировании перераспределения компонентов в процессе последующего вакуумного отжига являлись

$$
\begin{gathered}
C_{\mathrm{A}}(x, 0)=N_{\mathrm{SA}}, C_{\mathrm{B}}(x, 0)=C_{\mathrm{F}}(x, 0)=0 \text { при } 0 \leq x \leq h, \\
C_{\mathrm{A}}(x, 0)=0, C_{\mathrm{B}}(x, 0)=r N_{\mathrm{SF}}, C_{\mathrm{F}}(x, 0)=(1-r) N_{\mathrm{SF}} \\
\text { при } h<x \leq L, \\
C_{\mathrm{D}}(x, 0)=C_{\mathrm{C}}(x, 0)=0 \text { при всех } 0 \leq x \leq L,
\end{gathered}
$$

где $h$ - толщина пленки кобальта, $L-$ толщина пленки $\mathrm{TiO}_{2}, N_{\mathrm{SA}}-$ собственная концентрация атомов металла $\left(N_{\mathrm{SA}}=9.1 \cdot 10^{22} \mathrm{~cm}^{3}\right.$ для Со $), N_{\mathrm{SF}}-$ собственная концентрация атомов титана в его диоксиде $\left(N_{\mathrm{SF}}=3.2 \cdot 10^{22} \mathrm{~cm}^{-3}\right), r$ - доля реакционно способных атомов титана в его диоксиде.

Система уравнений (2)-(6) с концентрационно-зависимым эффективным коэффициентом взаимодиффузии (7) решалась численно методом факторизации с использованием консервативных неявных разностных схем [22].

Параметрами модели являлись: индивидуальные коэффициенты диффузии металлов, константа скорости $k_{1}$ реакции замещения титана кобальтом на границах зерен (1) и доля $r$ реакционно-способных атомов титана в пленке $\mathrm{TiO}_{2}$. Результаты численного моделирования представлены кривыми на рис. 4 и 5.

Численным анализом экспериментальных концентрационных распределений компонентов в рамках модели определены значения индивидуальных коэффициентов диффузии кобальта и титана. Температурная зависимость индивидуальных коэффициентов диффузии кобальта и титана приведена на рис. 6 (точки 1 и 2 для кобальта и титана соответственно). В диапазоне температур $923-1073 \mathrm{~K}$ они изменяются в пределах $D_{\mathrm{Co}}=6.4 \cdot 10^{-14}-1.7 \cdot 10^{-12} \mathrm{~cm}^{2} / \mathrm{s}$, $D_{\mathrm{Ti}}=1.2 \cdot 10^{-15}-4.5 \cdot 10^{-15} \mathrm{~cm}^{2} / \mathrm{s}$. При этих значениях параметров достигнуто хорошее соответствие экспериментальных распределений (точки 1-4) расчетным для полных концентраций кобальта $\left(C_{\mathrm{A}}+C_{\mathrm{D}}\right)$ (кривые $\left.I^{\prime}\right)$ и титана $\left(C_{\mathrm{B}}+C_{\mathrm{C}}+C_{\mathrm{F}}\right)$ (кривые $\left.2^{\prime}\right)$ (рис. 4,5) при неизменных $k_{1}=1 \cdot 10^{-24} \mathrm{~cm}^{3} / \mathrm{s}$ и $r=0.2$. Аппроксимация температурных зависимостей на рис. 6 уравнением Аррениуса дает в пленочной системе $\mathrm{Co}-\mathrm{TiO}_{2}$ для индивидуального коэффициента диффузии кобальта

$$
D_{\mathrm{Co}}=9.0 \cdot 10^{-4} \exp (-1.86 \mathrm{eV} /(k T)) \mathrm{cm}^{2} / \mathrm{s}
$$

и титана

$$
D_{\mathrm{Ti}}=1.2 \cdot 10^{-11} \exp (-0.73 \mathrm{eV} /(k T)) \mathrm{cm}^{2} / \mathrm{s} .
$$


Модель объясняет появление свободного титана на межфазной границе со стороны кобальта (рис. 4,5, кривые $2^{\prime \prime}$ ) как результат его замещения и диффузии в пленку кобальта. Перегиб на концентрационных распределениях полного кобальта (кривые $1^{\prime}$ ) на МФГ со стороны $\mathrm{TiO}_{2}$ обусловлен концентрационной зависимостью коэффициента взаимодиффузии (7) и захватом свободного кобальта (кривые $1^{\prime \prime}$ ) на межзеренных границах. Пологий участок распределения кобальта в оксиде титана отражает постоянство концентрации ловушечных центров по глубине пленки.

Глубокое проникновение $\mathrm{Co}$ в пленку $\mathrm{TiO}_{2}$ оказывается возможным из-за малой скорости реакции замещения кобальтом титана на поверхности зерен рутила. Действительно, оценка радиуса взаимодей-

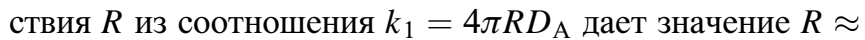
$\approx 4 \cdot 10^{-13} \mathrm{~cm}$, что значительно меньше типичных значений $(0.1-1) \cdot 10^{-8} \mathrm{~cm}$ для лимитируемых диффузией твердотельных реакций. Малая скорость реакции (1) обусловлена, по-видимому, высокой прочностью связи Ті-О.

\section{Заключение}

Комплексным исследованием взаимодиффузии и фазообразования в пленочной системе $\mathrm{Co}-\mathrm{TiO}_{2}$ при магнетронном распылении металла на оксид установлено существенное перемешивание компонентов, сопровождающееся образованием сложного оксида кобальта и титана $\mathrm{CoTi}_{2} \mathrm{O}_{5}$. В процессе последующего изотермического вакуумного отжига в интервале температур 573-1073 K формируется гетерофазная пленка, содержащая сложные оксиды на основе титана и кобальта: $\mathrm{CoTi}_{2} \mathrm{O}_{5}$ и $\mathrm{CoTiO}_{3}$. При всех температурах отжига сохраняется оксид титана в структуре рутила и металлический титан.

Предложен механизм формирования сложных оксидов, предполагающий реакционную диффузию переходного металла Со по межзеренным границам оксида титана (в структуре рутила), обратный поток высвобождающегося свободного титана и образование сложных оксидов по всей толщине пленки $\mathrm{TiO}_{2}$ на границах зерен. Разработана количественная модель, развивающая теорию [21] на случай реакционной взаимодиффузии в двухслойных пленочных поликристаллических системах металл-оксид с ограниченной растворимостью компонентов. Численным анализом экспериментальных концентрационных распределений компонентов в рамках разработанной модели реакционной взаимодиффузии определены значения индивидуальных коэффициентов диффузии кобальта и титана в системе $\mathrm{Co}-\mathrm{TiO}_{2}$ в диапазоне температур 923-1073 K. Модель позволяет хорошо описать основные закономерности процесса: появление титана в пленке кобальта и глубокое проникновение Со в пленку оксида титана, а также объяснить образование сложных оксидов не путем послойного роста на границе раздела металл-оксид, а по всей толщине пленки $\mathrm{TiO}_{2}$.

\section{Список литературы}

[1] Park W.K., Ortega-Hertogs R.J., Moodera J.S. et al. // J. Appl. Phys. 2002. Vol. 91. N 10. P. 8093. doi: $10.1063 / 1.1452650$

[2] Chambers S.A., Droubay T., Wang C.M. etal. // Appl. Phys. Lett. 2003. Vol. 82. N 8. P. 1257-1258. doi: $10.1063 / 1.1556173$

[3] Punnoose A., Seehra M.S., Park W.K. et al. // J. Appl. Phys. 2003. Vol. 93. N 10. P. 7867-7869. doi: 10.1063/1.1556121

[4] Kim D.H., Yang J.S., Lee K.W. et al. // Appl. Phys. Lett. 2002. Vol. 81. N 13. P. 2421. doi: $10.1063 / 1.1509477$

[5] Pan J.S., Chai J.W., Wang S.J. et al. // International J. Mod. Phys. B. 2008. Vol. 22. N 1-2. P. 63-69.

[6] Akdogan N., Nefedov A., Zabel H. etal. // J. Phys. D: Appl. Phys. 2009. Vol. 42. N 11. Article number 115005. doi: $10.1088 / 0022-3727 / 42 / 11 / 115005$

[7] Hu W., Hayashi K., Fukumura T. etal. // Appl. Phys. Lett. 2015. Vol. 106. N 22. Article number 222403. http://doi.org/10.1063/1.4921847

[8] Chai J.W., Pan J.S., Wang S.J. et al. // Surf. Sci. 2005. Vol. 589. N 1-3. P. 32-41.

[9] Fleischhammer M., Panthöfer M., Tremel W. // J. Sol. Stat. Chem. 2009. Vol. 182. N 4. P. 942-947. https://doi.org/10.1016/j.jssc.2009.01.011

[10] Ачкеев А.А., Хайбуллин Р.И., Тагиров Л.Р.идр. // ФТТ. 2011. Т. 53. Вып. 3. С. 508-517.

[11] Sasaki J., Peterson N.L., Hoshino K. // J. Phys. and Chem. of Sol. 1985. Vol. 46. N 11. P. 1267-1283. https://doi.org/10.1016/0022-3697(85)90129-5

[12] Joshi ShalikRam, Padmanabhan B., Chanda Anupama et al. // Appl. Surf. Sci. 2016. Vol. 387. P. 938-943. http://dx.doi.org/10.1016/j.apsusc.2016.07.038

[13] JCPDS - International Centre for Diffraction Data, 2012.

[14] Pärna R., Joosta U., Nõmmiste E. etal. // Appl. Surf. Sci. 2011. Vol. 257. N 15. P. 6897-6907.

[15] Samet L., Ben Nasseur J., Chtourou R. etal. // Materials Characterization. 2013. Vol. 85. P. 1-12. https://doi.org/10.1016/j.matchar.2013.08.007

[16] Chambers S.A., Thevuthasan S., Farrow R.F.C. et al. // Appl. Phys. Lett. 2001. Vol. 79. P. 3467-3469. http://doi.org/10.1063/1.1420434

[17] Matsumoto Y., Murakami M., Shono T. et al. // Science. 2001. Vol. 291. P. 854-856. doi: 10.1126/science. 1056186

[18] Fa-Min Liua, Peng Dinga, Xin-An Yangb, Jian-Qi Lib // Nuclear Instruments and Methods in Physics Research Section B: Beam Interactions with Materials and Atoms. 2009. Vol. 267. N 18. P. 3104-3108. http://dx.doi.org/10.1016/j.nimb.2009.06.030

[19] Yildırma O., Cornelius S., Smekhova A. et al. // Nuclear Instruments and Methods in Physics Research Section B: Beam Interactions with Materials and Atoms. 2016. Vol. 389-390. P. 13. http://dx.doi.org/10.1016/j.nimb.2016.11.009

[20] Smigelskas A.D., Kirkendall E.O. // Trans. AIME. 1947. Vol. 171. P. 130-142.

[21] Darken L.S. // Trans. AMIE. 1948. Vol. 175. P. 184-190.

[22] Самарский А.A. Теория разностных схем. М.: Наука, 1977. $656 \mathrm{c}$. 